\title{
Spontaneous omental bleeding: a case report and literature review
}

\author{
Yun-Xiao Lyu ${ }^{1,3^{*}} \mathbb{D}$, Yun-Xiao Cheng ${ }^{1}$ and Ting Li ${ }^{2}$
}

\begin{abstract}
Background: Spontaneous rupture of omental vessels is an infrequent medical condition possibly causing severe intra-abdominal hemorrhage. Omental bleeding results from trauma associated injury and irritation, neoplasia, arterial aneurysm rupture, and anticoagulant treatment. Idiopathic omental bleeding rarely causes acute abdominal bleeding which has been reported to occur in previous studies. Here we reported a case with idiopathic omental hemorrhage due to vascular malformation. A systematic review of literature is provided.

Case presentation: A 58-year-old Han Chinese man arrived at the emergency department with left upper quadrant abdominal pain for 1 day. He had no significant previous medical history. There was no history of fever, vomiting, nausea, or anorexia. He was a non-smoker and did not consume alcohol. On physical examination, blood pressure was $118 / 72 \mathrm{mmHg}$, for a temperature of $37.7^{\circ} \mathrm{C}$; heart and respiratory rates of $130 \mathrm{per} / \mathrm{min}$ and $20 \mathrm{per} / \mathrm{min}$ were obtained, respectively. Abdomen assessment showed only mild tenderness in the left upper quadrant. Complete blood count (CBC) showed white cell and platelet counts of $16.69 \times 10^{3} / \mathrm{L}$ and $196 \times 10^{3} / \mathrm{L}$, respectively. The haemoglobin value was $13.5 \mathrm{~g} / \mathrm{L}$ at admission. Abdominal Computer Tomography (CT) was performed that showed peritoneal fluid appeared around the liver. Fresh blood was confirmed in the abdominocentesis. A hemoperitoneum was confirmed by abdominal enhanced $C T$, which presented a structural disorder in the left upper abdomen. The subject immediately underwent exploratory laparotomy. A massive hemoperitoneum originating from omental vessels was observed. The omental were partially removed. There was no evidence of malignancy or aneurysm upon palpation. Pathological assessment of the extracted tissue pointed to vascular malformation. The patient subsequently had an uneventful recovery; hospital discharge occurred at 7 days post-operation.

Previous reports assessing idiopathic omental bleeding were systematically reviewed, summarizing published cases. A total of 12 hits were found in PubMed for idiopathic omental bleeding.

Conclusion: Idiopathic omental bleeding is a rare condition that requires emergency treatment. Treatment strategies include surgical intervention and transcatheter arterial embolization (TAE). The surgical option is suitable in subjects with persistent hypotension and those with unconfirmed diagnosis.
\end{abstract}

Keywords: Omental bleeding, Diagnosis, Computerd tomography, Surgery, Transcatheter arterial embolization

\section{Background}

Spontaneous rupture of omental vessels is an infrequent medical condition which causes serious intra-abdominal bleeding. Omental bleeding can result from trauma associated injury and irritation, neoplasia [1], arterial aneurysm rupture [2], and treatment with anticoagulants

\footnotetext{
* Correspondence: Ivyunxiao1986@gmail.com

'Department of Hepatobiliary Surgery, Dongyang People's Hospital, No. 60, West Wuning Road, Dongyang, Jinhua, Zhejiang, China

${ }^{3}$ Department of General Surgery, Dongyang People's Hospital, No. 60, West

Wuning Road, Dongyang 322100, Zhejiang Province, China

Full list of author information is available at the end of the article
}

[3]. Idiopathic omental bleeding rarely causes acute abdominal bleeding which has been reported to occur in previous studies. Here, we reported a case with idiopathic omental hemorrhage due to vascular malformation. In addition, previous reports were systematically reviewed.

\section{Case presentation}

A 58-year-old Han Chinese man arrived at the emergency department with left upper quadrant abdominal pain for 1 day. He had no significant previous medical history. There was no history of fever, vomiting, nausea, or anorexia. He was a non-smoker and did not consume

(c) The Author(s). 2018 Open Access This article is distributed under the terms of the Creative Commons Attribution 4.0 International License (http://creativecommons.org/licenses/by/4.0/), which permits unrestricted use, distribution, and 
alcohol. On physical examination, blood pressure was $118 / 72 \mathrm{mmHg}$, for a temperature of $37.7^{\circ} \mathrm{C}$; heart and respiratory rates of $130 \mathrm{per} / \mathrm{min}$ and $20 \mathrm{per} / \mathrm{min}$ were obtained, respectively. Abdomen assessment showed only mild tenderness in the left upper quadrant. Complete blood count $(\mathrm{CBC})$ showed white cell and platelet counts of $16.69 \times 10^{3} / \mathrm{L}$ and $196 \times 10^{3} / \mathrm{L}$, respectively. The haemoglobin value was $13.5 \mathrm{~g} / \mathrm{L}$ at admission. Abdominal Computer Tomography (CT) was performed that showed peritoneal fluid. In order to clarify the nature of peritoneal effusion,abdominocentesis was performed. Fresh blood was confirmed in the abdominocentesis. We could not identify the source of bleeding through abdominal CT. A hemoperitoneum was confirmed by abdominal CT with contrast enhancement, which presented a structural disorder in the left upper abdomen (Fig. 1). The subject immediately underwent exploratory laparotomy. A massive hemoperitoneum originating from omental vessels was observed. The omental were partially removed. There was no evidence of malignancy or aneurysm upon palpation. Pathological assessment of the extracted tissue pointed to vascular malformation(Fig. 2). Our pathologist found that it is venous malformation with the damage of the venous wall continuity accompanied with the overflow of large number of red blood cells. The patient subsequently had an uneventful recovery; hospital discharge occurred at 7 days post-operation.

Previous reports assessing idiopathic omental bleeding were systematically reviewed, summarizing published cases. A total of 12 hits were found in PubMed for idiopathic omental bleeding.

\section{Review of the literature}

The PubMed (2000-2017) database was queried for case reports of idiopathic omental bleeding. The abstracts of all articles published in the English language were screened.

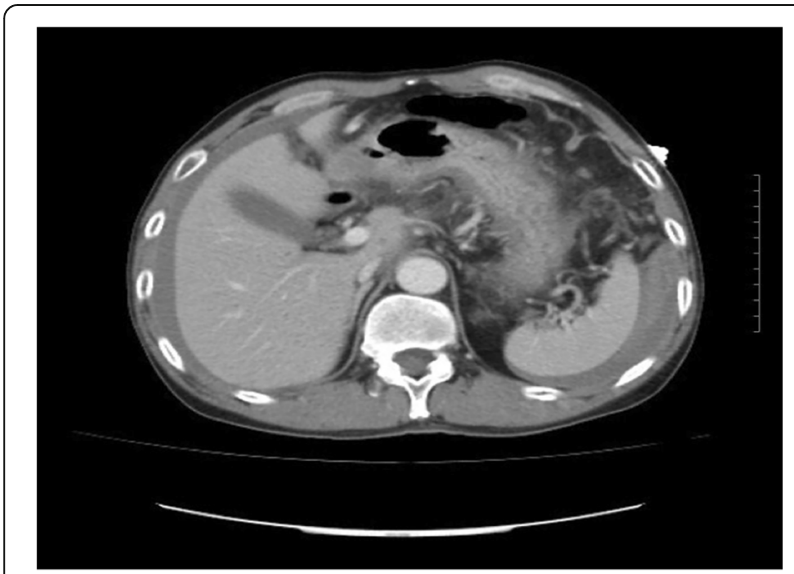

Fig. 1 Abdominal CT scan. The CT-scan receals structural disorder of the left upper abdominal and hemoperitoneum

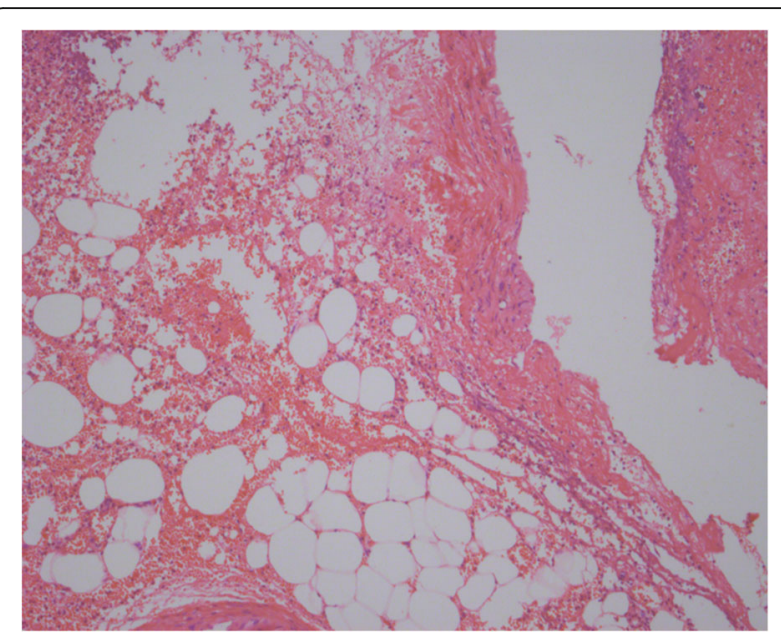

Fig. 2 Pathology examination. The pathology reveals the the vascular malformations of omental

Patient data, including age, diagnostic and treatment procedures, were extracted.

A total of 12 articles were found in PubMed for idiopathic omental bleeding, including ours [4-15]. Relevant findings are summarized in Table 1 . The patients included 11 males and 1 female, aged between 20 and 70 years. The diagnostic procedures included $\mathrm{CT}$ and laparotomy. The patients underwent emergency surgery $(n=8)$ or transcatheter arterial embolization(TAE) $(n=4)$.

\section{Discussion and conclusions}

Idiopathic omental bleeding, although sparse in this part of the world, is considered one of the causes of spontaneous hemoperitoneum. Spontaneous omental bleeding is a serious condition, with a mortality rate exceeding $30 \%$ [16]. Several causes of spontaneous omental bleeding have been reported, including neoplasia, arterial aneurysm, vasculitis, and anticoagulant therapy. A patient administered sildenafil citrate succumbed to the rupture of an omental varix [5]. However, there are few reports of idiopathic omental bleeding. The ages of patients with idiopathic omental bleeding range between the 20s and the 80s; it has a male predominance. Acute intraabdominal hemorrhage, abdominal pain and distension, tachycardia, and hypotension, constitute typical signs of idiopathic omental bleeding; severe cases present with abdominal compartment syndrome [17]. Some cases series assessing omental bleeding suspected appendicitis or peritonitis preoperatively $[10,18]$. The diagnostic assessment of idiopathic omental bleeding is essentially based on imaging procedures, especially ultrasonography (US) and CT. US facilitated hemoperitoneum detection in the current hemodynamically unstable subject. US is considered as an effective method. However, in our hospital, US needs to be done by a professional ultrasound-doctor. However, CT 
Table 1 Reports of idiopathic omental hemorrhag

\begin{tabular}{|c|c|c|c|c|c|c|c|c|}
\hline First of author & Year & Coutry & F/M & Age & Chief complaint & Post medical history & $\begin{array}{l}\text { Diagnostic } \\
\text { procedure }\end{array}$ & Treatment \\
\hline Kroot EJ [7] & 2003 & Netherlands & M & $70 y$ & Abdominal pain & NA & $C T$ & Surgery \\
\hline Finely DS [5] & 2005 & USA & M & $41 y$ & $\begin{array}{l}\text { Abdominal pain } \\
\text { Difficulty seeing }\end{array}$ & $\begin{array}{l}\text { Alcoholic cirrhosis } \\
\text { (took a unkonwn } \\
\text { dose of sidenafi) }\end{array}$ & $\begin{array}{l}\text { Hemoglobin } \\
\text { drop }\end{array}$ & Ligate the omental varix \\
\hline Ohno T [10] & 2005 & Japan & M & $27 y$ & $\begin{array}{l}\text { Intermittent abdominal } \\
\text { pain }\end{array}$ & $\begin{array}{l}\text { Surgery for } \\
\text { cryptorchidism }\end{array}$ & CT & Partial omentalectomy \\
\hline Jadav M [6] & 2004 & USA & M & $60 y$ & $\begin{array}{l}\text { Acute abdominal pain } \\
\text { Nausea,voimiting and } \\
\text { diarrha }\end{array}$ & Hypertension & laparotomy & Surgery \\
\hline Nagaba Y [9] & 2005 & Japan & M & $64 y$ & $\begin{array}{l}\text { Acute abdominal pain } \\
\text { hemorrhagic shock }\end{array}$ & $\begin{array}{l}\text { Autosomal-dominant } \\
\text { polycystic kidney disease }\end{array}$ & CT & TAE \\
\hline Tsuchiya R [12] & 2009 & Japan & M & $58 y$ & abdominal pain & NA & $C T$ & TAE \\
\hline Matsumoto T [8] & 2010 & Japan & M & $25 y$ & Abdominal pain & NA & $C T$ & TAE \\
\hline Henry D [13] & 2012 & USA & $\mathrm{F}$ & $24 y$ & $\begin{array}{l}\text { malaise, myalgias, and } \\
\text { fatigue }\end{array}$ & NA & laparotomy & Surgery \\
\hline Takahashi M [11] & 2012 & Japan & M & $27 y$ & $\begin{array}{l}\text { abdominal pain. } \\
\text { temporary loss of } \\
\text { consciousness }\end{array}$ & NA & $C T$ & TAE \\
\hline Cheng VE [4] & 2014 & Australia & M & $68 y$ & $\begin{array}{l}\text { acutely hypotensive } \\
\text { with severe left sided } \\
\text { abdominal pain }\end{array}$ & $\begin{array}{l}\text { Inferior STEMI } \\
\text { ticagrelor and } \\
\text { aspirin }\end{array}$ & $\mathrm{CT}$ & Partial omentectomy \\
\hline Aumann V [14] & 2016 & Germany & M & 20 & NA & Hemophilia A & NA & Surgery \\
\hline Kimura J [15] & 2016 & Japan & M & 29 & Abdominal pain & NA & CT & Partial omentectomy \\
\hline
\end{tabular}

NA not avaliable, CT computer tomography, TAE transcatheter arterial embolization

(especially enhanced CT) is the most effective imaging tool since signals corresponding to hemoperitoneum, active arterial extravasation, and mesenteric fluid might help radiologists determine the origin of hemorrhage and guide treatment [16]. Abdominocentesis can be a useful diagnostic tool in distinguishing the characteristic of peritoneal fluid. However, abdominocentesis is an invasive procedure which can be lead to intestinal perforation and abdominal wall abscess. When the patient's condition is unstable, it may be appropriate to have a laparotomy or a laparoscopy.

Regardless of the underlying etiology of idiopathic omental bleeding, aggressive treatment is preferable. Idiopathic omental is routinely treated by surgical procedures, including ligation or omentectomy. In most cases reported, however, an emergency surgery was performed. The surgical option is suitable in subjects with persistent hypotension and those with unconfirmed diagnosis. Surgery is often carried out because few cases are correctly diagnosed pre-treatment. However, TAE for idiopathic omental bleeding has been reported previously $[8,9,11,12]$. TAE is a safe and minimally invasive procedure, with the advantages of simultaneous diagnosis and treatment. Therefore, TAE might represent the best therapeutic option for idiopathic omental bleeding. It should be carried out with caution in patients with proximal embolization due to risk of rebleeding via the collateral circulation. A therapeutic scheme is proposed for the treatment of idiopathic omental bleeding in this study.

In summary, idiopathic omental bleeding is an infrequent condition requiring emergency treatment; typical manifestations include acute intraperitoneal hemorrhage. US and CT scan are useful for its diagnosis. Treatment strategies include surgical intervention and TAE. In subjects with persistent hypotension or cases with unconfirmed diagnosis, surgery might be suitable.

\section{Abbreviations}

CT: Computed Tomography; TAE: Transcatheter arterial embolization; US: Ultrasound

\section{Acknowledgements}

The authors thanks Kang-Fei San who povided the medical images on behalf of the Derpartment of Radiology,Department of General Surgery, Dongyang people's Hospital.

\section{Authors' contributions \\ Author contributions: $Y X L$ and $T L$ searched the literature. $Y X L$ conceived of the study, participated in its design and drafted the manuscript, and final revision of the manuscript. YXC participated in the collection of the clinical data and design of the study All authors read and approved the final manuscript.}

Ethics approval and consent to participate

Not applicable.

\section{Consent for publication}

Written informed consent was obtained from the patient for publication of this Case report and any accompanying images. A copy of the written consent form is available for review by the Editor of this journal. 


\section{Competing interests}

The authors declare that they have no competing interests.

\section{Publisher's Note}

Springer Nature remains neutral with regard to jurisdictional claims in published maps and institutional affiliations.

\section{Author details}

'Department of Hepatobiliary Surgery, Dongyang People's Hospital, No. 60, West Wuning Road, Dongyang, Jinhua, Zhejiang, China. ²Dongyang People's Hospital, No. 60, West Wuning Road, Dongyang, Jinhua, Zhejiang, China. ${ }^{3}$ Department of General Surgery, Dongyang People's Hospital, No. 60, West Wuning Road, Dongyang 322100, Zhejiang Province, China.

\section{Received: 6 September 2017 Accepted: 22 May 2018}

Published online: 30 May 2018

\section{References}

1. Dixon AY, Reed JS, Dow N, Lee SH. Primary omental leiomyosarcoma masquerading as hemorrhagic ascites. Hum Pathol. 1984;15(3):233-7.

2. Borioni R, Garofalo M, Innocenti P, Fittipaldi D, Tempesta P, Colagrande L, Seddio F, Pace A. Hemoperitoneum due to spontaneous rupture of an aneurysm of the left gastroepiploic artery. J Cardiovasc Surg. 1999;40(1):63-4.

3. Adelman MI, Gishen P, Dubbins P, Mibashan RS. Localised intramesenteric haemorrhage-a recognisable syndrome in haemophilia? Br Med J. 1979; 2(6191):642-3.

4. Cheng VE, Oppermen A, Natarajan D, Haikerwal D, Pereira J. Spontaneous omental bleeding in the setting of dual anti-platelet therapy with ticagrelor. Heart Lung Circ. 2014;23(4):e115-7.

5. Finley DS, Lugo B, Ridgway J, Teng W, Imagawa DK. Fatal variceal rupture after sildenafil use: report of a case. Curr Surg. 2005;62(1):55-6.

6. Jadav M, Ducheine Y, Brief D, Carter L, McWhite T, Hardy J. Abdominal apoplexy: a case study of the spontaneous rupture of the gastroepiploic artery. Curr Surg. 2004;61(4):370-2.

7. Kroot EJ, Mak CL, Boelhouwer RU, Middelkoop MP, Dees A. Involvement of the omentum in Wegener's granulomatosis. Ann Rheum Dis. 2003;62(12):1238-9.

8. Matsumoto T, Yamagami T, Morishita H, lida S, Tazoe J, Asai S, Masui K, Ikeda J, Nagata A, Sato O, et al. Transcatheter arterial embolization for spontaneous rupture of the omental artery. Cardiovasc Intervent Radiol. 2011;34(Suppl 2):S142-5.

9. Nagaba $Y$, Nishimaki H, Ichinoe M, Okuwaki $Y$, Hamura M, Makino T, Sano T, Higashihara M, Kamata K, Soma K. Spontaneous rupture of a left gastroepiploic artery aneurysm in a patient with autosomal-dominant polycystic kidney disease. Clin Nephrol. 2005;63(2):163-6.

10. Ohno T, Ogata K, Aiba S, Fukuchi M, Osawa H, Mogi A, Motegi M, Nagashima K, Ishizaki M, Mochiki E, et al. Idiopathic omental bleeding: report of a case. Surg Today. 2005;35(6):493-5.

11. Takahashi M, Matsuoka Y, Yasutake T, Abe H, Sugiyama K, Oyama K. Spontaneous rupture of the omental artery treated by transcatheter arterial embolization. Case Rep Radiol. 2012;2012:273027.

12. Tsuchiya R, Takahashi S, Takaoka T, Mineoka Y, Nakabe N, Sakamoto N, Boku Y, Kanasaki S, Yoshikawa T. A case of idiopathic omental bleeding treated successfully with transarterial embolization. Nihon Shokakibyo Gakkai zasshi = The Japanese journal of gastro-enterology. 2009;106(4):554-9.

13. Henry D, Satgunam S. Idiopathic omental bleeding. J Surg Case Rep. 2012;2012(9):2.

14. Aumann V, Chiapponi C, Meyer F, Wybranski C, Bruns CJ, Jannasch O. Spontaneous omental bleeding in a 20-year old patient with hemophilia A. A rare cause for emergency laparotomy. Hamostaseologie. 2016;36(Suppl. 2):S22-4.

15. Kimura J, Okumura K, Katagiri H, Lefor AK, Mizokami K, Kubota T. Idiopathic omental hemorrhage: a case report and review of the literature. Int J Surg Case Rep. 2016;28:214-8.

16. Lucey BC, Varghese JC, Anderson SW, Soto JA. Spontaneous hemoperitoneum: a bloody mess. Emerg Radiol. 2007;14(2):65-75.

17. Kasotakis G. Spontaneous hemoperitoneum. Surg Clin North Am. 2014:94(1):65-9.

18. Nihei Z, Kojima K, Uehara K, Sawai S, Kakihana M, Hirayama R, Mishima Y. Omental bleeding with spontaneously derotated torsion-a case report. Jpn J Surg. 1991;21(6):700-2.

\section{Ready to submit your research? Choose BMC and benefit from:}

- fast, convenient online submission

- thorough peer review by experienced researchers in your field

- rapid publication on acceptance

- support for research data, including large and complex data types

- gold Open Access which fosters wider collaboration and increased citations

- maximum visibility for your research: over $100 \mathrm{M}$ website views per year

At BMC, research is always in progress.

Learn more biomedcentral.com/submission 